\title{
sciendo
}

\section{Nonlinear optimisation approach to proposing novel Croatian Industrial Confidence Indicator}

\author{
Mirjana Čižmešija \\ University of Zagreb, Faculty of Economics \& Business, Croatia \\ mcizmesija@efzg.hr \\ Zrinka Lukač \\ University of Zagreb, Faculty of Economics \& Business, Croatia \\ zlukac@efzg.hr \\ Tomislav Novoselec \\ Microline d.o.o., Croatia \\ tomislav_novoselec@yahoo.com
}

\begin{abstract}
Croatian Industrial Confidence Indicator (ICI) is one of the measures of mangers' sentiment about the economic situation in the Croatian manufacturing industry. Since 2005, the $\mathrm{ICl}$ has been calculated in accordance with the harmonised European Commission methodology as a simple average of three variables: order books, stocks of finished products and production expectation. It was empirically confirmed that the $\mathrm{ICl}$ could predict the direction of change in industrial production more than one month ahead. With the aim of raising the $\mathrm{ICI}$ forecasting power, this paper proposes a novel $\mathrm{ICl}$ with a different weighting scheme. The empirical analysis is based on monthly data for three standard $\mathrm{ICl}$ subcomponents and industrial production expressed as year-on-year growth rates. The data set covers the period from May 2008 to February 2019. Data sources were the European Commission and Eurostat. The newly defined $\mathrm{ICl}$ was constructed by using the nonlinear optimisation approach. The weights were determined by minimizing the root mean square error (RMSE) in a simple regression model and by maximizing the correlation coefficient between the $\mathrm{ICl}$ and industrial production for various time lags. The results reveal that the newly defined $\mathrm{ICl}$ performs better in adapting and following the industrial production growth rate as well as that the dominant component in the $\mathrm{ICl}$ is the production expectation.
\end{abstract}

Keywords: business and consumer survey, industrial confidence indicator, nonlinear optimisation.

JEL classification: C53, C61, E32.

DOI: 10.2478/crebss-2019-0008

Received: July 01, 2019

Accepted: September 16, 2019 


\section{Introduction}

Business and Consumer Survey (BCS) and BCS confidence indicators in different economic sectors have become an integral part of macroeconomic modelling. Using confidence indicators, the direction of change in a reference series can be predicted one or more months ahead. Confidence indicators are calculated for five different sectors and for the national economy as a whole. There are confidence indicators for manufacturing industry, construction, retail trade, services and for consumers. For example, change in the industrial confidence indicator predicts change in industrial production, and so on. The composite indicator on the macroeconomic level is Economic Sentiment Indicator (ESI). In the last time, ESI has been postulated as a very important leading indicator in forecasting changes in overall economic activity. Methodology for the construction of the European BCS and for the calculation of the BCS confidence indicators are harmonised by the Joint Harmonised EU Programme of Business and Consumer survey established in 1961. In accordance with this Program, Confidence indicators (excluding ESI) are calculated as arithmetic mean of seasonally adjusted balances of answers to the selected variables in BCS (European Commission, 2019). For example, Industrial Confidence Indicator (ICl), as the composite indicator of business climate in manufacturing industry, is an arithmetic mean of seasonally adjusted balances of three variables: (1) order book, (2) production expectation and (3) stock of the finished products (with inverted sign), where balance is a difference between weighted percentages of positive and negative answers of firms on corresponding questions (variables).

Given the fact that the ICl's forecasting power in predicting the direction of change in industrial production has been empirically confirmed (Čižmešija, Bahovec, 2009), the main idea and the research goal of this paper is to modify ICl in order to improve its forecasting power. The hypothesis is that by changing the weights in calculation of $\mathrm{ICl}$ the predictive power of $\mathrm{ICI}$ may raise, with respect to year-on-year industrial production growth rates. The main inspiration in establishing the research goal was the recent empirical survey conducted by Sorić et al. (2016), where authors determined the new weights in calculation of ESI by minimizing the root mean square error (RMSE) in simple gross domestic product (GDP) forecasting regression equation and by maximizing the correlation coefficient between ESI and GDP growth for various leading times. They estimated the GDP forecasting equations by OLS method where ESI was the predictor variable for various leading times. The novel weighting scheme for 26 EU member states improved ESI's forecasting accuracy. With that in mind, in this paper we propose a novel $\mathrm{ICl}$ weighting scheme for Croatian $\mathrm{ICl}$ constructed by using nonlinear optimisation techniques.

This paper is organised as follows: Section 2 presents literature review about using confidence indicators in forecasting reference macroeconomic variables. Section 3 presents the methodology and empirical data set. The results are presented in section 4 , while the last section contains the main conclusion.

\section{Literature review}

Recent global economic recession, financial crisis and their impact on the real economy have particularly inspired many analysts and researchers to investigate the relationship between economic sentiment and macroeconomic and financial variables. It is a well-known fact that economic sentiment indicators have the predictive power for many economic variables, like GDP growth, household spending, unemployment, income, inflation and many others. This is no surprise since ESI 
expresses economic sentiment in all BCS sectors (manufacturing industry, construction, retail trade, services sector and among consumers).

The link between BCS confidence indicators and economic activity is widely covered in the literature, but the existing theoretical and empirical studies of the economic sentiment mainly have investigated the ESI's predictive power of macroeconomic variables. Another BCS confidence indicator often used as a measure of the sentiment is the Consumer confidence indicator (CCI). It is usually used as a predictor of the private consumption. Some other indicators, such as confidence indicators in construction, retail trade and in services sector are used less then ESI and $\mathrm{CCl}$.

The literature about the relationship between $\mathrm{ICl}$ and other macroeconomic variables is relatively modest, especially in Croatia. In Croatia, in about $60 \%$ of cases changes in $\mathrm{ICl}$ correctly predict changes in industrial production with one quarter ahead. Our assumption that the "predictive power of ICl" should rise is based on the results from Soric et al. (2016). Investigation of new ICl's prediction power is the goal for the next empirical research. First, it has been known that in many economies (like in Croatia), ICl is used as a proxy of ESI due to the dominant share of industrial production in GDP and the fact that $\mathrm{CCl}$ can be a proxy for ESI in predicting changes in GDP or in industrial production. Therefore, the literature review presented below will be useful in understanding the main research goals presented in this paper.

Čižmešija and Sorić (2010) investigated the potentiality of using ESI as a short-term leading indicator of Croatian GDP and its main components. Using a bivariate VAR, authors have shown that changes in GDP can be explained more accurately when we include ESI in models.

Čižmešija et al. (2011) analysed the relationship between $\mathrm{ICl}$ and the manufacturing industry in the EURO Area. Based on regression analyses, the conclusion was that in accordance with $\mathrm{ICl}$ change the direction of change in industrial production (for the same month) could be predicted. Here one has to have in mind that business survey results are available before the official statistics are published, so the ICl's forecasting power is evident. Čižmešija and Bahovec (2009) confirmed the possibility of forecasting the direction of change in Croatia's industrial production with $\mathrm{ICl}$.

Some empirical studies have shown the existence of the relationship between consumer sentiment and stock market returns (Jansen, Nahuis, 2003; Akhtar et al., 2011; Hsu et al. 2011; Bathia et al., 2016; Lolic et al. 2017). Piccoli et al. (2018), by using the $\mathrm{CCl}$, found that the relationship between conditional variance and stocks returns is positive (negative) in periods of low (high) sentiment.The exceptions are small financial markets. They have a negative relationship among the analysed variables. The sharp growth in the number of less sophisticated investors under these circumstances is a result of the high impairment of the positive relationship between risk and return when the sentiment is high. Many recent researches use $\mathrm{CCl}$ as a proxy for the investor sentiment (Piccoli et al., 2018, Aydogan, 2017, Bathia et al., 2016).

Cristiansen et al. (2014) combined sentiment variables with other classical recession predictors of financial and some other macroeconomic variables. Sentiment variables showed significant predictive power for US recessions.

Economic sentiment as a predictor of the rate of growth of the real GDP, using different econometric models, was analysed by Mazurek and Mielcova (2017), Largent (2017), Osterholm (2014), Utaka (2014), Horvath (2012), Eickmeier and Ng (2011), Howrey (2001) and many others. All of them derived similar conclusions that sentiment indicators either by themselves or in conjunction with other leading indicators can be used in forecasting changes in GDP, with 3 to 6 months lead. 
Soric (2018) investigated the time-varying impact of consumer sentiment on GDP growth. He conducted the empirical analysis using a state space model with timevarying coefficients. He used the dataset from 11 New EU Member States. He found that the impact of consumer sentiment significantly increased in the 2008, which means that the recent crisis was to some extent psychologically governed. After that, the impact of consumer sentiment on GDP mostly stabilizes at the earlier levels.

The idea to include sentiment variables in predicting economic activity is not new, but the scope of application of these variables is wider than before. Shayaa et al. (2018) investigated linking $\mathrm{CCl}$ and social media big data via sentiment analysis. The results indicated that the significant but very small relationship between $\mathrm{CCl}$ and social media sentiment analysis exists. Brodeur (2018) analysed the effect of terrorism on consumer sentiment. Guntner and Linsbaver (2018) investigated the effects of oil supply and demand shocks on the University of Michigan's Index of Consumer Sentiment. They found that the expectations of future inflation and change in real household income as well as perceived vehicle and house-buying conditions are the main transmission channels of oil supply and demand shocks. Čižmešija and Orlović (2018) investigated the relationship between turnover in retail trade and the $\mathrm{CCl}$ on the aggregate level of the European Union and on the aggregate level of Euro zone. They concluded that the changes in $\mathrm{CCl}$ precede the changes in retail trade turnover by two (for the EU) and three (for EA) months and that their planned and achieved changes are significantly correlated.

Yoo (2018) empirically analysed the relationship between Consumer sentiment and trading volume in Korean Housing Market. The main conclusion is that $\mathrm{CCl}$ and trading volume behave similarly. Based on this conclusion, the suggestion is that the $\mathrm{CCl}$ and trading volume are crucial for policy-making and stability management of the housing market. Kłopocka (2017) analysed household savings and borrowing behaviour in Poland in relationship with the consumer confidence. The survey results were twofold. First, the $\mathrm{CCl}$ has predictive power for future household saving and borrowing rates. Second, consumer confidence index contains information about future household saving and borrowing rates aside from the information contained in other available indicators. The link between consumer sentiment and inflation was analysed in Ahmedl and Cassou (2016), Biaowolski (2016), Erjavec et al. (2015), Sorić (2013) and many others.

All the papers mentioned above confirmed significant relationship among economic and consumer confidence on one side and financial, economic and some other macroeconomic variables on the other side. Therefore, indicators of economic and consumer confidence can be useful in macroeconomic forecasting.

\section{Methodology}

The empirical analyses conducted in this research is based on monthly data for three standard ICl subcomponents expressed as balances of three BCS questions: order books, stock of finished products and production expectation. Namely, $\mathrm{ICl}$ is an arithmetic mean of seasonally adjusted balances of three variables: (1) order book, (2) production expectation and (3) stock of the finished products (used with inverted sign). Balances per question are seasonally adjusted using Dainties as the seasonaladjustment method, developed by Eurostat. Variable of stock of finished products is inversely correlated with the industrial production as a referent series. Therefore, it is included in the indicator calculation with an inverted sign. Survey questions used in preparing balances are given in Table Al. The aim of the research is to construct novel $\mathrm{ICl}$ with the new weighting scheme for Croatian BCS, focused on improving ICl's forecasting quality. With that in mind, the reference series used in empirical research 
is the industrial production expressed as year-on-year growth rates (in accordance with the harmonised European BCS methodology). The time series considered refers to the period from May 2008 to February 2019. The BCS results are obtained from the European Commission, while the industrial production data are gathered from Eurostat. It is well known that $\mathrm{ICl}$ precedes to the rate of changes in industrial production (HR_ind_y-o-y index), therefore various prognostic horizons $h$ are considered $(h=0,1,2, \ldots, 12)$.

The abbreviations used in the paper are as follows: Q2 - order books, Q4 - stock of finished products and Q5 - production expectation, ICI_HR - standard Industrial Confidence Indicator, ICI_N - new Industrial Confidence Indicator, HR_ind_y-o-y - the rate of changes in industrial production.

For each prognostic horizon $h, h=0,1,2, \ldots, 12$, we consider the simple regression model:

$$
H R_{-} \text {ind }-y-o-y_{t+h}=\alpha+\beta\left(w_{1} Q_{2}-w_{2} Q_{4}+w_{3} Q_{5}\right)+\varepsilon_{t}
$$

where $\alpha$ and $\beta$ are regression parameters and $w_{1}, w_{2}$ and $w_{3}\left(w_{1}+w_{2}+w_{3}=1\right)$ are the non-negative weights obtained by minimizing the root mean square error (RMSE) for the simple regression model. Therefore, parameters $\alpha$ and $\beta$ as well as the weights $w_{1}$, $w_{2}$ and $w_{3}$ are obtained by solving the optimization problem (2):

$$
\min _{\alpha, \beta, w_{1}, w_{2}, w_{3}} \sqrt{\frac{1}{T-h-2} \sum_{t=1}^{T-h}\left[\text { HR_ind_y-o-y } \mathrm{y}_{\mathrm{t}+\mathrm{h}}-\alpha-\beta\left(w_{1} Q_{2, t}-w_{2} Q_{4, \mathrm{t}}+w_{3} Q_{5, t}\right)\right]^{2}}
$$

subject to

$$
\begin{aligned}
& w_{1}+w_{2}+w_{3}=1 \\
& w_{1}, w_{2}, w_{3} \geq 0
\end{aligned}
$$

where $Q_{2, t}, Q_{4, t}$ and $Q_{5, t}$ denote corresponding values for time period t. Solving the optimization model (2) is equivalent to solving the optimization model (3):

$$
\min _{\alpha, \beta, w_{1}, w_{2}, w_{3}} \sum_{t=1}^{T-h}\left[\text { HR_ind_y-o-y } \mathrm{t}_{\mathrm{t}+\mathrm{h}}-\alpha-\beta\left(w_{1} Q_{2, t}-w_{2} Q_{4, \mathrm{t}}+w_{3} Q_{5, t}\right)\right]^{2}
$$

subject to

$$
\begin{aligned}
& w_{1}+w_{2}+w_{3}=1 \\
& w_{1}, w_{2}, w_{3} \geq 0
\end{aligned}
$$

which is a quadratic optimization problem and therefore easier to solve than optimization model (2).

Let $\alpha^{h}, \beta^{h}, w_{1}^{h}, w_{2}^{h}$ and $w_{3}^{h}$ denote the optimal solution of model (3) for each prognostic horizon $h, h=0,1,2, \ldots, 12$. Now, for each $h$ we define the new ICl (ICl_N) as:

$$
I C I_{-} N^{h}=\alpha^{h}+\beta^{h}\left(w_{1}^{h} Q_{2}-w_{2}^{h} Q_{4}+w_{3}^{h} Q_{5}\right) .
$$

In order to perform the robustness check of the new indicators $I C I N N^{h}$ obtained by solving the optimisation problem (3) for different $h$, we analyse the $\mathrm{ICI} \mathrm{N}^{h}$ 's forecasting power by using the Pearson's correlation coefficient between $\mathrm{ICI} \mathrm{N}^{h}$ and the rate of 
change in industrial production (HR_ind_y-O-y) for the same forecasting horizons $(h=0,1,2, \ldots, 12)$.

\section{Empirical results}

The "optimal" weights for the new $\mathrm{ICl} \_\mathrm{N}$ are obtained by solving the optimisation problem (2) (3). The results are presented in Table 1 It which brings the values of $\alpha^{h}, \beta^{h}, w_{1}^{h}, w_{2}^{h}$ and $w_{3}^{h}$ for different values of prognostic horizons $h, h=0,1,2, \ldots, 12$.

Table 1 Optimization results - ICls components weights

\begin{tabular}{|c|c|c|c|c|c|}
\hline $\begin{array}{c}\text { Forecasting } \\
\text { horizon } \boldsymbol{h}\end{array}$ & $\begin{array}{c}\text { Parameter } \\
\boldsymbol{\alpha}\end{array}$ & $\begin{array}{c}\text { Parameter } \\
\boldsymbol{\beta}\end{array}$ & ${\text { Weight } \mathbf{w}_{\mathbf{1}}}$ & ${\text { Weight } \mathbf{w}_{\mathbf{2}}}$ & ${\text { Weight } \mathbf{w}_{\mathbf{3}}}$ \\
\hline 0 & -5.3176 & 0.2460 & 0.0000 & 0.0000 & 1.0000 \\
1 & -5.3275 & 0.2473 & 0.0000 & 0.0000 & 1.0000 \\
2 & -5.3303 & 0.2477 & 0.0000 & 0.0000 & 1.0000 \\
3 & -5.0869 & 0.2632 & 0.0000 & 0.0802 & 0.9197 \\
4 & -5.3719 & 0.2573 & 0.0000 & 0.0054 & 0.9945 \\
5 & -5.3283 & 0.2706 & 0.0000 & 0.0493 & 0.9506 \\
6 & -5.3563 & 0.2769 & 0.0000 & 0.0550 & 0.9449 \\
7 & -5.3528 & 0.2792 & 0.0000 & 0.0571 & 0.9428 \\
8 & -5.4097 & 0.2796 & 0.0000 & 0.0386 & 0.9613 \\
9 & -5.3854 & 0.2847 & 0.0000 & 0.0557 & 0.9442 \\
10 & -5.3647 & 0.2903 & 0.0000 & 0.0712 & 0.9287 \\
11 & -5.3402 & 0.2947 & 0.0000 & 0.0845 & 0.9154 \\
12 & -5.4298 & 0.2982 & 0.0000 & 0.0638 & 0.9361 \\
\hline
\end{tabular}

Source: Authors' calculation.

The standard $\mathrm{ICl}$ is defined as the simple average of seasonally adjusted balances of variables Q2, Q4 and Q5, and therefore here $w_{1}=w_{2}=w_{3}=1 / 3$. However, if we want to minimize the RMSE in industrial growth rate, different weighting schemes should be applied for different prognostic horizons. It is evident that the dominant component in ICl_N has to be Q5 - production expectation $(h=0,1, \ldots, 12)$. Its weight is equal to 1 in $h=0,1,2$. After that, $w_{3}$ decreases as the forecasting horizon increases. Nevertheless, $w_{1}$ is 0 for all forecasting horizons. It means that $Q 2$ - order books is not important in calculation of the ICI_N. The presence of variable Q4 - stock of finished products is minor too. As we can see from Table 1, $w_{2}$ is 0 for $h=0,1,2$. After that, $w_{2}$ slowly increases.

Table 2 shows the correlation of $\mathrm{ICl}$ HR and new index $\mid C I \_N^{h}, h=0,1, \ldots, 12$, with HR_ind_y-o-y. As we can see from Table 2, the correlation of $I C I \_N^{h}$ with HR_ind_y-O-y is the greatest for $h=2$. It outperforms the correlation of ICl_HR with HR_ind_y-O-y. Furthermore, the RMSE for ICI_N2 is 43.8052, while the RMSE for ICI_HR is 109.1313, which shows that $\mathrm{ICI} \mathrm{N}^{2}$ outperforms ICl_HR index regarding the RMSE as well. 
Table 2 Optimization results - correlation ICI_Nh with HR_ind_y-O-y

Source: Authors' calculation.

\begin{tabular}{|c|c|}
\hline $\begin{array}{c}\text { Forecasting } \\
\text { horizon } h\end{array}$ & $\begin{array}{c}\text { Correlation of } \\
\text { ICI_Nh with } \\
\text { HR_ind_y-O-y }\end{array}$ \\
\hline 0 & 0.6895 \\
\hline 1 & 0.6739 \\
\hline $\mathbf{2}$ & $\mathbf{0 . 6 9 1 7}$ \\
\hline 3 & 0.6448 \\
\hline 4 & 0.5954 \\
\hline 5 & 0.5153 \\
\hline 6 & 0.4718 \\
\hline 7 & 0.4575 \\
\hline 8 & 0.4036 \\
\hline 9 & 0.3867 \\
\hline 10 & 0.3463 \\
\hline 11 & 0.3013 \\
\hline 12 & 0.2763 \\
\hline ICI_HR & $\mathbf{0 . 6 4 3 6}$ \\
\hline
\end{tabular}

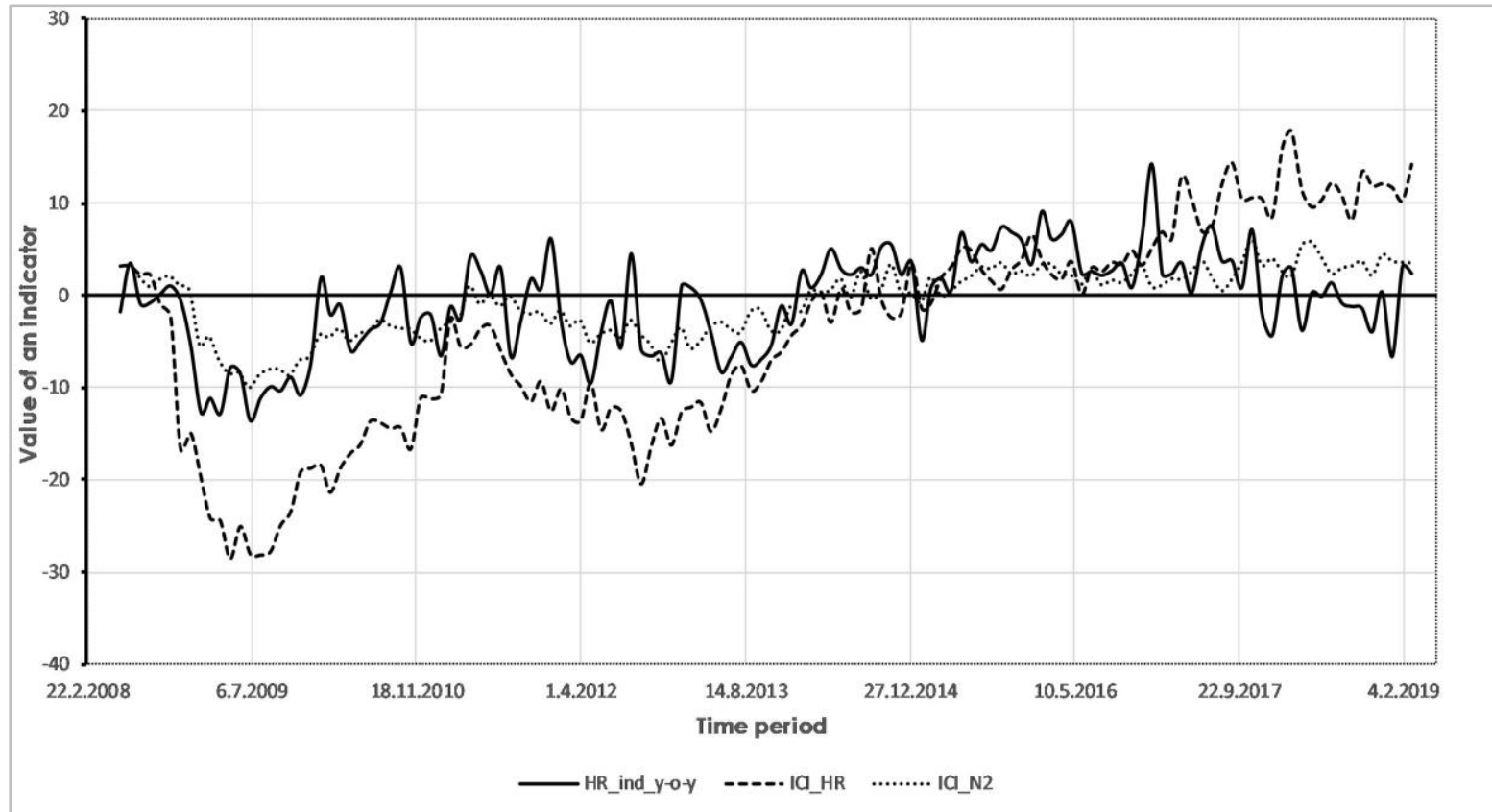

Figure 1 The value of the indicators $H R \_$ind_y-O-y, $I C l \_H R$ and $I C I \_N^{2}$ over time Source: Authors' creation.

The main conclusion derived from the empirical results presented in Table 1 and Table 2 can be seen in Figure 1. It is evident that the new $\mathrm{ICl}$ with the different weighting scheme better adapts and follows the HR_ind_y-o-y curve ( $h=2)$.

\section{Conclusion}

Croatian BCS has been part of the Joint Harmonised EU Programme of Business and Consumer Surveys since May 2005. Survey methodology and the methodology of calculating confidence indicators are unified. In accordance with that standard methodology, confidence indicators in four different sectors are defined as simple averages of seasonally adjusted balances of selected variables. The $\mathrm{ICl}$ as a measure 
of managers' sentiment in manufacturing industry is a simple average of three components: order books, stock of finished products and production expectation. All of them have equal weights in $\mathrm{ICl}$.

In this paper, we proposed the novel weighting scheme in calculation of $\mathrm{ICl}$. The weights are obtained by using the nonlinear optimisation approach with the goal of increasing the $\mathrm{ICl}$ forecasting power in predicting changes in industrial production. By minimizing the RMSE in industrial growth rate, we derived different weighting schemes for different prognostic horizons. The dominant component in $\mathrm{ICl}$ has to be the production expectation. The variable order book is not important in calculation of the $\mathrm{ICl}$ and the presence of variable stock of finished products is of minor importance.

The results obtained confirmed the main hypothesis of this paper that the three variables of which the $\mathrm{ICl}$ is constructed do not have equal weights in calculation of $\mathrm{ICl}$ as a predictor of changes in industrial production rate in Croatia. By changing the weights in calculation of $\mathrm{ICl}$, the predictive power of $\mathrm{ICl}$ may rise, with respect to yearon-year industrial production growth rates. BSC provide valuable information for economic short-term forecasting and detecting turning points in the business cycles. All improvements of the predictive power of the BCS indicator are welcome. The results of empirical research presented in this paper are part of the ongoing efforts to produce indicators with better predictive power then the standard one. The limitation of the survey is relatively small data set in Croatia's BCS.

Encouraged by the results of our research for Croatia's $\mathrm{ICl}$, the future research will be focused on other EU countries and other BCS sectors like construction, retail trade and services sector.

\section{References}

1. Ahmedl, M. I., Cassou, S. P. (2016). Does consumer confidence affect durable goods spending during bad and good economic times equally? Journal of Macroeconomics, Vol. 50, pp. 86-97.

2. Akhtar, S., Faff, R., Oliver, B., Subrahmanyam, A. (2011). The power of bad: the negativity bias in Australian consumer sentiment announcements on stock returns. Journal of Banking and Finance, No. 35, pp. 1239-1249.

3. Aydogan, B. (2017). Sentiment dynamics and volatility of international stock markets. Eurasian Business Review, Vol. 7, No. 3, pp. 407-419.

4. Bathia, D., Bredin, D., Nitzsche, D. (2016). International Sentiment Spillovers in Equity Returns. International Journal of Finance \& Economics, Vol. 21, No. 4, pp. 332-359.

5. Biaowolski, P. (2016). The influence of negative response style on survey-based household inflation expectations. Quality \& Quantity, Vol. 50, No. 2, pp. 509-528.

6. Brodeur, A. (2018). The Effect of Terrorism on Employment and Consumer Sentiment: Evidence from Successful and Failed Terror Attacks. American Economic Journal - Applied Economics. Vol. 10, No. 4, pp. 246-282.

7. Čižmešija, M., Bahovec, V. (2009). Forecasting the direction of changes in Croatia's industrial production with ICl and CROLEl. Revista Investigación Operacional, Vol. 30, No. 2, pp. 140148.

8. Čižmešija, M., Orlović, Z. (2018). Consumer Confidence Indicator as a Leading Indicator of Changes in Retail Trade Turnover. Ekonomski pregled, Vol. 69, No. 1, pp. 3-19.

9. Čižmešija, M., Sorić, P. (2010). Assessing Croatian GDP components via Economic Sentiment Indicator. Ekonomska istraživanja, Vol. 23, No. 4, pp. 1-10.

10.Čižmešija, M., Copak, M., Kurnoga Živadinović, N. (2011). Industrial Confidence Indicator and Manufacturing Industry in the EURO Area, Proceedings of the $11^{\text {th }}$ International Symposium on Operational Research SOR '11. Zadnik Stirn, L., Žerovnik, J., Povh, J., Drobne, S., Lisec, A. (editors), Ljubljana: Slovenian Society Informatika, Section for Operational Research, pp. 221-226. 
11.Cristiansen, C., Eriksen, J. N., Moller, S. V. (2014). Forecasting US Recessions: The Role of Sentiments. Journal of Banking \& Finance, No. 49, pp. 459-468.

12. Eickmeier, S., Ng, T. (2011). Forecasting national activity using lots of international predictors: An application to New Zealand. International Journal of Forecasting, Vol. 27, No. 2, pp. 496511.

13.Erjavec, N., Lolić, I., Sorić, P. (2015). How (i)rrational are we? A case of Croatian inflation. Croatian Operational Research Review, Vol. 6, No. 1, pp. 241-253.

14.European Commission (2019). A user guide to the Joint Harmonised EU Programme of Business and Consumer Surveys. Available at https://ec.europa.eu/info/business-economyeuro/indicators-statistics [19 June 2019].

15.Guntner, J. H. F., Linsbauer, K. (2018). The Effects of Oil Supply and Demand Shocks on US Consumer Sentiment. Journal of Money Credit and Banking, Vol. 50, No. 7, pp. 1617-1644.

16. Horvath, R. (2012). Do Confidence Indicators Help Predict Economic Activity? The Case of the Czech Republic. Finance a Uver_Czech Journal of Economics and Finance, Vol. 62, No. 5, pp. 398-412.

17. Howrey, E. P. (2001). The Predictive Power of the Index of Consumer Sentiment. Brookings Papers on Economic Activity, No. 1, pp. 175-207.

18. Hsu C. C., Lin H. Y., Wu J. Y. (2011). Consumer Confidence and Stock Markets: The Panel Causality Evidence. International Journal of Economics and Finance, Vol. 3, No. 6, pp. 435480.

19.Janson, W. J., Nahuis, N. J. (2003). The Stock Market and Consumer Confidence: European Evidence. Available at http://www.technicalanalysis.org.uk/sentiment/JaNa02.pdf [05 October 2019].

20.Kłopocka, A. M. (2017). Does Consumer Confidence Forecast Household Saving and Borrowing Behavior? Evidence for Poland, Social Indicators Research, 133(2), pp. 693-717.

21.Largent, Y. M. (2017). The Deficit and Public Debt Dynamics in bad and good Times. Revue Economique, Vol. 68, No. 4, pp. 571-594.

22.Lolić, I., Sorić, P., Čizmesija, M. (2017). Personal Finances vs. the Overall Economic Conditions: What Drives the New EU Member States' Stock Markets? Comparative Economic Research - Central and Eastern Europe, Vol. 20, No. 4, pp. 125-142.

23. Mazurek, J., Mielcova, E. (2017). Is Consumer Confidence Index a suitable predictor of future economic growth? An evidence from the USA. E\&M Ekonomie a Mnagement, Vol. 20, No. 2, pp. 30-45.

24.Osterholm, P. (2014). Survey data and short-term forecasts of Swedish GDP growth. Applied Economics Letters, Vol. 21, No. 2, pp. 135-139.

25.Piccoli, P., Costa, N.C.A., da Silva, W.V., Cruz, J.A. W. (2018). Investor sentiment and the riskreturn tradeoff in the Brazilian market. Accounting and Finance, Vol. 58, No. 1, pp. 599-618.

26.Shayaa, S., Ainin, S., Jaafar, N. I., Zakaria, S. B., Phoong, S. W, Yeong, W. C., Al-Garadi, M.A., Muhammad, A., Piprani, A. Z. (2018). Linking consumer confidence index and social media sentiment analysis. Cogent Business \& Management, Vol. 5, No. 1, pp. 1-12.

27.Sorić, P. (2013). Assessing the sensitivity of consumption expenditure to inflation sentiment in post-communist economies. Post-Communist Economies, Vol. 25, No. 4, pp. 529-538.

28.Sorić, P. (2018). Consumer confidence as a GDP determinant in New EU Member States: a view from a time-varying perspective. Empirica, Vol. 45, No. 2, pp. 261-282.

29.Sorić, P., Lolić, I., Čižmešija, M. (2016) European Economic Sentiment Indicator: An empirical reappraisal. Quality \& quantity, Vol. 50, No. 5, pp. 2025-2054.

30.Utaka, A. (2014). Consumer Confidence and the Japanese Economy -Comparison of Preand Post-Bubble Period. Economics Bulletin, Vol. 34, No. 2, pp. 1165-1173.

31.Yoo, H. (2018). The Relationship between Consumer Sentiment Index and Trading Volume in Housing Market - Focused on Fundamental Component and Transitory Component. Journal of Real Estate Policy Research, Vol. 19, No. 2, pp. 21-36. 


\section{About the authors}

Mirjana Čižmešija, PhD, is Full Professor at Department of Statistics, Faculty of Economics and Business Zagreb (FEB). Her doctoral thesis' topic Statistical and methodological background of business tendency surveys was defended in 2001 at FEB. Her research interests include business and consumer surveys, statistical methods for management decision-making and business forecasting. She has been working on numerous research projects, out of which, founded by Croatian Science Foundation, stand out: The role of economic sentiment in explaining macroeconomic trends: methodological improvements and new areas of application (as a project leader) and Economic sentiment: statistical, political, behavioural, and media aspects of its influence on economic activity (as a researcher). She has published more than 100 scientific articles and studies. She has been a reviewer for many respectable international journals, some of which are Quality \& Quantity, Economic Research and The World Economy. She is a member of the review panels of Croatian Science Foundation and Swiss National Science Foundation, and she is the member of the editorial board of several scientific journals and conferences. She was Head of Department of Statistics and President of the FEB Graduate Studies Committee. The author can be contacted at mcizmesija@efzg.hr.

Zrinka Lukač, PhD, is Full Professor at Department of Mathematics, Faculty of Economics and Business Zagreb (FEB), where she teaches at the undergraduate and doctoral program, as well as at the English-taught undergraduate program. She obtained the BSc degree in Pure Mathematics from Faculty of Science, Department of Mathematics, University of Zagreb, and MSc degree in Operational Research, as well as PhD degree in Economics from Faculty of Economics and Business Zagreb (FEB). She was a Fulbright Scholar at Leeds School of Business, University of Colorado. From 2012-18 she was Head of Department of Mathematics at FEB. Currently she has been President of the Croatian Operational Research Society. Her research interests lie primarily in the area of the Operational Research and Optimization. She is member of the editorial board of several scientific journals and conferences and Editor in Chief of Croatian Operational Research Review journal. Author can be contacted at zlukac@efzg.hr.

Tomislav Novoselec graduated in 2013 at Faculty of Economics and Business Zagreb (FEB). In 2015, he continued education at doctoral study programme at FEB. Within his scientific work, he has been engaged at FEBs Department of Statistic. In the meantime, he has published article titled Influence of financing source on the small business performance. Currently he is working as an accountant in Microline d.o.o. and doing research on PhD thesis theme Impact of the entrepreneurs' personality characteristics on the financial position and business performance of micro entities. Author can be contacted at tomislav_novoselec@yahoo.com.

\section{Appendix}

Table A1 Questions and answers in BCS - Industrial confidence indicator

\begin{tabular}{l} 
Q2: Do you consider your current overall order books to be...? \\
+ more than sufficient (above normal) \\
= sufficient (normal for the season) \\
- not sufficient (below normal) \\
\hline Q4: Do you consider your current stock of finished products to be...? \\
+ to large (above normal) \\
= adequate (normal for the season) \\
- to small (below normal) \\
\hline $\begin{array}{l}\text { Q5: How do you expect your production to develop over the next } 3 \text { months? It will } \\
\text { + increase } \\
\text { = remain unchanged } \\
\text { - decrease }\end{array}$ \\
\hline
\end{tabular}

